\title{
ADDRESSING ORGANIZATIONAL ISSUES IN REQUIREMENTS ENGINEERING PRACTICE: LESSONS FROM ACTION CASES
}

\author{
Jim Hughes and Trevor Wood-Harper \\ Information Systems Institute, University of Salford, Salford. M5 $4 W T$. UK \\ and School of Accounting and Information Systems, University of South Australia, Adelaide. South Australia
}

\begin{abstract}
The requirements phase of information systems development is arguably the most organizationally dependent phase and as such it could be contended that the methods used in this phase ought to explicitly address organizational issues. However the authors would maintain that there is a weakness in many of the methods that are employed in requirements engineering in that they are not explicitly embedded within any social scientific perspective. We argue that such a perspective would enable the systems developer to address organizational contexts and to engage with users (social actors) in such a way that it may be possible to find out about their social situations and as a consequence better inform the systems development process. In this paper we present the arguments for an explicit organizational perspective in the requirements phase of information systems development. We illustrate the argument through the presentation of action case studies in which one of the authors intervened in two situations with an explicit sociological perspective and analysis methods more commonly associated with qualitative social science methods. We conclude that there is an imperative need for those involved in the requirements phase to be explicit in their assumpions about organizations and critically reflective about the methods they use if they wish to understand the domain in which they operate.
\end{abstract}

\section{INTRODUCTION}

The authors maintain that there is a critical weakness in many of the methods employed in the requirements determination phase of information systems development since although the methods may have an underpinning philosophical basis, they are not explicitly embedded in any social scientific perspective. Such a perspective would enable methods or methodologies to address the organizational contexts in which their use may be envisaged. In other words, for information systems development purposes, traditional methods have been used which are based on a philosophical paradigm that is intended to give a technological perspective. In view of the directions from which many information systems researchers have arrived (Adam and Fitzgerald, 1996) it perhaps is not surprising that their ideas in the realm of organizational analysis may appear to some to be epistemologically unsound. The issue here is that any analysis which aspires to reveal details of particular aspects of organizational life needs to reflect an ontological and epistemological rationale for the study of organizations as complex systems. That is to say, until it is decided what is knowable about organizations, and how such knowledge might be arrived at, the eclectic use of what may be labelled 'convenient' analysis instruments poses a threat to any serious progress. The fundamental question which must be addressed from the outset by a systems developer in any organizational or social setting, is 'what is going on?' or, more pointedly, 'how do I make sense of, and understand, what is going on?'

In the traditional inquiry methods requirements engineers may bring assumptions into the organizational domain that may have little or no relevance to the context in which the questions are being asked. These assumptions may not be explicit and therefore may as a consequence never be examined. If for example requirements engineers set out to discover why people hold particular points of view, or why people in a particular part of the organization behave in a certain way then they must first be able to explain why such a discovery is important or relevant. It is against this background that the issues are addressed.

The paper is structured as follows: It begins with a critique of the classical approach to requirements engineering and then proposes an alternative 'situated' approach. This is followed by two illustrative action cases. The treatment of the cases provides an explicit organizational perspective for intervention, describes the interventions and the outcomes from them. The paper concludes with a discussion of the major issues - the value of situated requirements and the implications for the role of the requirements engineer.

\section{A CRITIQUE OF CLASSICAL REQUIREMENTS ENGINEERING}

The classical approach to requirements elicitation revolves around the role of the requirements engineer and in using a term such as engineering it therefore constrains the process to be largely technical. Indeed the main role of the requirements engineer is said to be to 'capture' requirements. The suggestion being that requirements may be difficult to find but they exist in a deterministically fixed form and indeed the implication is that there is a finite number of them to be found. The classical methods also tend to be restricted to questionnaire and interview but as Jirotka and Goguen, (1994) note "the analysis of the materials gathered is largely left to intuition" (Jirotka and Goguen, p.4, 1994). In practice most requirements specifications, which are considered to be the product of a requirements elicitation exercise, are written in natural language supported by diagrams that conform to some predetermined standard. Examples of standards of this type are the STARTS Handbook (NCC, 1989). McDermid (1994) identifies the structure of typical orthodox requirements specifications and these are shown in figure 1. Here the core of the specification is a set of function definitions, setting out the 
functions to be performed by the system which are supported by a description of the structure of the data to be processed. McDermid notes that global considerations of requirements may also be included but these tend to more problematic since they deal with properties that may be considered to be emergent rather than be decomposable. Typically then if the functionality and other non-functional properties can be decomposed into modules then these may be allocated to software engineers to implement.

The problem with this approach to requirements elicitation is that although the specification may be considered to be well written it may not be appropriate. As Valusek and Fryback (1985) explain, the process of information requirements determination is a process which incorporates obstacles within individual users, among users and between users and systems developers. In the case of obstacles among users they maintain that users' descriptions or definitions of similar functions or requirements may be quite different.

Typical functional specifications cover, at least

- normal functioning, including inputs, outputs, operation, and control

- abnormal functioning, exceptions etc.

- dependability properties eg safety and security

- performance eg throughput

- quality eg maintainability or modifiability

- expected changes

Data specifications:

- definition of data structure

- volumetrics, eg data flow rate

- sources and sinks of data

Figure 1. Structure of typical orthodox requirements specification (adapted from McDermid, p.24, 1994)

Furthermore, the meaning that systems developers attribute to the responses in interviews or questionnaires, that is their interpretation, may be different from the meaning held by the users. It is the obstacles within individual users that Valusek and Fryback claim has received little attention, that is the problems associated with the understanding of the user due to cognitive limitations on memory, recall and judgement - what Davis (1982) calls the constraints on humans as information processors and problem solvers. In the case where the specification is to have a level of detail to enable software engineers to code then these human centred problems are exacerbated rather than mitigated.

There is also the problem in validating requirements, a problem linked to the above, because of the semantics of natural language (Auramaki et al., 1988). As McDermid (1994) notes somewhat cynically the validation process for such specifications merely documents 'what it is that the analyst thought it was the problem owner said he thought he might want, not what he'll get!'. It is possible more recently to see the requirements engineering community addressing the domain problem through the introduction of techniques such as ViewPoints (Easterbrook and Nuseibeh, 1995) and the Use Case approach (Regnell et al., 1993; Jacobson, 1992). Others address domain analysis (Frakes et al., 1998a, 1998b) and elsewhere a domain theory for requirements engineering (Sutcliffe and Maiden, 1998). However whilst they recognise the evolutionary and conflicting nature of the requirements process and attempt to deal with the complexity of requirements they may be considered to stay true to the classical formalisation roots. Further examples include the recognition by Jackson (1998) that requirements engineers are vitally concerned with describing a mostly informal world in which "it is almost impossible to give a complete and formal description" (Jackson 1998, p.74). However his response is to attend to the 'accuracy' of the descriptions used implying an organizational assumption that there is some given reality which can be both captured and described. We accept that there are those who are not so critically aligned to the requirements engineering tradition since some question the mechanistic view of requirements capture. Dzida and Freitag (1998) for example point to the use of scenarios for requirements 'construction' rather than 'capture' and Potts and Newstetter (1997) note the growing appreciation for naturalistic inquiry derived from the anthropological and the ethnomethodological traditions. However these views remain in a minority amongst the requirements engineering community.

This is not, as it may seem, a return to the lengthy debate about 'hard' versus 'soft'. For example a method of understanding complex problem domains such as Soft Systems Methodology (SSM) (Checkland, 1981; Checkland and Scholes, 1990) whilst gaining popular appeal has been criticised from some quarters. Brown (1992) criticises SSM on the grounds that it is flawed as a mainstream sociological research approach and there are inherent weaknesses in the first two stages of SSM - the finding out stages - which provides only the most impressionistic guidelines for the capture and analysis of data. As noted by Dobbie and Hughes (1993), this has opened the door to possible expediency in the application of inquiry methods and methodologies. That is to say that in the worst case requirements engineers, or indeed SSM practitioners, may use methods and methodologies in the organizational domain without regard to any explicit organizational perspective.

Specifically for requirements engineers it is argued here that what is required is an approach which deals with the explicit recognition of the organizational and social dimensions of requirements (Hughes et al., 1993; 
Goguen and Linde, 1993). It is very much in the spirit of Potts and Newstetter's (1997) assertion that naturalistic inquiry techniques incorporated into the requirements process must not be seen simply as 'a set of slick tools' but that to deliver their potential they must be 'taken with their philosophical baggage intact'. Below we consider the basis for such naturalistic inquiry and in doing so we explicitly elucidate the philosophical underpinnings and the organisational perspective of the inquiry.

\section{AN ALTERNATIVE VIEW - SITUATED REQUIREMENTS}

An alternative view of the prevalent requirements process is that proposed by Goguen (1992) in which he discusses the relationship between formal, context insensitive information which he terms 'dry' and informal, situated information which he terms 'wet'. The problem for Goguen in presenting 'dry' - 'wet' is the possible reconciliation between seemingly mutually exclusive states and he maintains that

"Formal information occurs in the syntactic representations used in computer-based systems. Informal situated information arises in social interaction, for example, between users and managers, as well as their interactions with systems analysts. Thus requirements engineering has a strong practical need to reconcile the dry and the wet" (Goguen 1992, p.1)

The resolution is all the more difficult since the expression of context sensitive requirements is usually through the use of natural language. Yet Goguen notes that features of natural language such as ambiguity, and lack of explicit structure can be advantageous since these can facilitate the gradual evolution of requirements. Also natural language is often the medium preferred by the individuals who represent the client. Interestingly this also highlights a shift in the perspective of requirements. The move is away from requirements being considered as the means by which systems developers can proceed with systems design and implementation and towards a perspective that requirements can be expressed in order that clients (users) can readily understand them. The suggestion being that the richest way of eliciting context sensitive information is to use the words and meanings that the clients use in the settings in which the clients act and interact with each other. In sociological terms this perspective is known as ethnomethodology which is the study of everyday procedures (methodology) that people in social situations (ethno) use to create, sustain and manage a sense of their social setting. For those involved in the requirements elicitation process this may be interesting and useful for collecting high quality data about social interaction but it does not apply to the analysis of data. An attempt to overcome this analysis issue in a practical domain is discussed later in the paper. What is needed first is to understand that the essential feature of this kind of study is that it attends to social data, which is situated. That is to say that the data can only be fully understood in relation to the particular, concrete situation in which it occurred.

Much of the work in the area of situated action derives from studies made by Lucy Suchman (1987). Suchman, an anthropologist, whilst not explicitly concerned with requirements determination, has made an important contribution to this area because in trying to understand fields such as cognitive science and human computer interface she constructs accounts of the relations among people including the 'culturally constituted' worlds that they inhabit. She maintains that the strategy for investigation is one in which the researcher/analyst can make sense of everyday activities and the contexts in which they arise. Hence she largely draws on ethnomethodology as the sociological basis for her work. Therefore in using the word 'situated' Suchman is concerned with events that occur in some interaction which can only be fully understood in relation to the particular concrete situation in which they actually occurred. Goguen (1994) provides six points derived from Suchman's work that he considers to be the qualities of 'situatedness' and these are given in Figure 2. For requirements determination, point 6 in figure 2. identifies that by considering any situation much of the practical knowledge is unarticulated and therefore for a requirements engineer the methods used for the analysis of the good quality data that ethnomethodology can produce is to determine (some of) the tacit grounded knowledge. One possible method for analysing the good quality data to determine the grounded knowledge is to use ethnomethodology principles together with Grounded Theory (Glaser and Strauss, 1967). Grounded Theory is a method from the social sciences used for the collection and analysis of qualitative data. Using its procedures as a guideline the requirements engineer abstracts categories from interview transcripts and produces a natural language account that links the categories together. The following section briefly describes two consultancies in which Grounded Theory and ethnomethodology were used to elicit situated requirements (Hughes and Wood-Harper, 1999). 
- Emergent Social events can not be understood at the level of the individual, that is, in terms of individual psychology, because the members of some group through their interaction jointly construct them as social events.

- Local. Actions and their interpretations are constructed in some particular context, including a particular place and time.

- Contingent. The construction and interpretation of events depends upon the current situation (potentially including the current interpretation of prior events). In particular interpretations are subject to negotiation, and relevant rules are interpreted locally, and can even be modified locally.

- Embodied. Actions are linked to bodies that have particular physical contexts, and that the particular way that bodies are embodied in a context may be essential to the social interpretation of some events.

- Open. Theories of social events (both those constructed by participants and by requirements engineers) cannot in general be given a final and complete form, but must remain open to revision in the light of further analyses and events.

- Vague. Practical information is only elaborated to the degree that it is useful to do so; the rest is left grounded in tacit knowledge.

Figure 2. The qualities of situatedness (adapted from Goguen 1994, p.168)

\section{ILLUSTRATIVE ACTION CASE STUDIES}

In this section the authors present two action cases to illustrate the ideas discussed above in a practical context. The objective of the action cases was primarily to elicit situated requirements to inform a more formal requirements engineering exercise. It should also be noted that it is not our intention to suggest that requirements engineers should adopt the methods discussed. The purpose of the illustration is to suggest how an explicit organizational perspective together with appropriate methods may assist the requirements engineer to better understand and make sense of the organizational domain. We begin this section by briefly outlining the action case method and the development of the conceptual framework that informed the intervention.

\section{Action Case}

The use of the term 'action case' follows from Vidgen and Braa (1997) who approach action case as arising from 'soft' case study which is essentially a method for understanding in which there may also be some limited intervention, which causes change. It is used here from an alternative perspective in which intervention is planned and from which some understanding is gained about the conceptual framework in order that learning can take place. The term is also intended to convey that the learning may be achieved in a limited number of interventions. Indeed a single intervention for a practitioner should be sufficient to reflect and learn about some project. In terms of action research the term action case may be characterised as 'reflective action research' as discussed by Baskerville and Wood-Harper (1998) in which they maintain that the critical element 'is the actors' discovery of where their behaviour is unexplained by their own understanding'. They note that within reflective action research 'iteration is no longer an end in itself'. This is clearly important for the practitioner since even within a single requirements project he/she may focus on the distinction between what was suggested by the theoretical framework versus what actually happened in practice. A consequence of this is the learning about the theoretical framework and the process of requirements engineering.

Furthermore, action case as used in the illustrative research presented here has a strong resonance with the concept of 'double loop learning' as expressed by Argyris and Schon (1978). They consider double loop learning to mean that following some intervention in an organization it is possible to learn about the domain they refer to this as single loop learning. However the learning may also challenge the 'norms' or framework which were the basis of the intervention. They suggest that this could cause some conflict amongst managers who established the norms. They refer to double loop learning as a resolution of the conflict. Indeed as Reason (1994) notes double loop learning is critical, since without the reflection on the 'governing variables', or theoretical framework, then it is possible for individuals to produce self-fulfilling systems of action which may lead to escalating errors. As mentioned earlier in this paper this is a possible consequence of a requirements engineering intervention without an explicit organizational perspective to help understand what is going on.

\section{Conceptual Framework}

The conceptual framework comprised the conjunction of ethnomethodology as a paradigm of inquiry and Grounded Theory as a method for data analysis. Action case was the research strategy for reflection on the 
domains. The ethnomethodological perspective and the rationale and procedures for Grounded Theory are described briefly below.

Ethnomethodological study focuses on how social actors (users in the requirements context) accomplish, manage and reproduce a 'sense' of social structure. Ethnomethodologists focus on folk (common) methods and common sense reasoning. Garfinkel (1967) refers to this as, 'the investigation of the rational properties of indexical expressions and other practical actions as contingent ongoing accomplishments of organized artful practices of everyday life.' Since reality is produced by way of actors' interpretive procedures then the ethnomethodologists maintain that the actors' social circumstances are 'self-generating' which implies two important properties. Firstly that meanings are essentially indexical, that is they depend on context and therefore it is only in the situated use of talk and interaction that objects and events become meaningful. Secondly that social realities are reflexive which is to say that interpretive activities are both in and also about the social settings that they describe. Thus the focus for ethnomethodological research is the treatment of talk and interaction as topics for analysis rather than merely as a means of communicating some underlying phenomena. Waters (1994) proposes that for ethnomethodologists the only way in which sociologists can reveal the 'facticity' of social experience is to approach it as would an anthropologist. He maintains that the sociologist must seek to understand situations in the terms in which participants give accounts of them. Furthermore sociologists must somehow induce participants to give accounts and thus to reveal the 'contextually rational properties of their social arrangements'.

Grounded Theory or as it is more properly titled 'The Discovery of Grounded Theory' (Glaser and Strauss, 1967) is a method for the analysis of qualitative data. The original work had three main purposes. Firstly, it was intended to offer the rationale for theory that was 'grounded', that is to say generated and developed through the inductive analysis of data collected during research projects. The use of the term 'theory' is used in the sense that it refers to local empirical models devised on the basis of data. The second aim was to suggest the procedures and the reasons for them and the third aim was to propose legitimacy for careful qualitative research. In the method conceptual properties and categories may be 'discovered' or generated from the qualitative data by following a number of guidelines and procedures.

There are two critical stages of Grounded Theory identified by Glaser and Strauss. Firstly that of 'constant comparative analysis', a procedure for the identification of conceptual categories and their properties which may be embedded in the data and secondly what they call 'theoretical sampling' which is both a category enriching and disconfirming procedure. These are depicted in figure 3 . The procedures are intended to indicate the primacy of the actors in the social setting. It is they who provide the transcript data, usually from interviews. As soon as the first transcript is prepared coding begins. At this stage it is 'open coding' and is fairly unrestricted in the sense that each line of the transcript is scrutinised and sometimes each word of each line to produce a code which at first may seem almost to be simply repetition or a summary of the text.

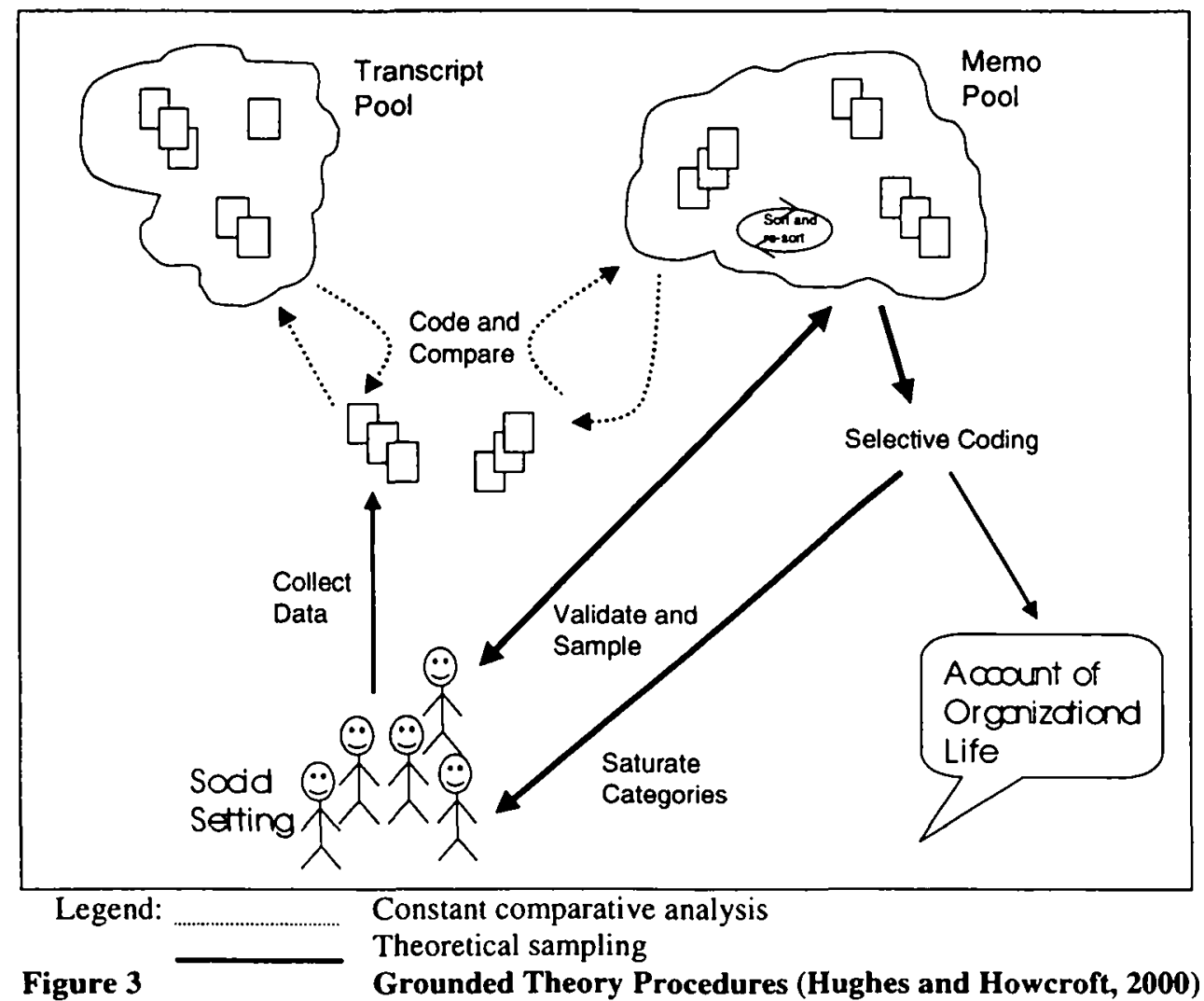


The purpose is to 'open' the inquiry into the data and at this stage any part of the data may seem relevant and if it is not then later it can be discarded. As more data is collected the analyst continues the open coding but also begins to identify 'categories' rather than labels. The categories are formed from groups of words from the initial coding which pertain to the same phenomenon. Categories are at a higher level and more abstract than the concepts they represent. The concepts must be repeatedly present in the data to warrant the abstraction to the level of category. The analyst may select both in vivo categories or the analyst's own categories. The categories are generated through the same analytic process as that above of making comparisons to highlight similarities and differences. For the process to be rigorous the analyst must go back through the currently available data and re-code in relation to the new categories. Analysts may then use their knowledge of the domain, or their previous experience, to expand and clarify categories to sensitise themselves to ways of further exploring the data. As categories are formed it is essential that each has associated with it a memo which elucidates it and relates it back to the data. As the number of categories increase they can be related to each other and to sub-categories. This process is known as 'axial' coding in which the analyst explores the relationship amongst categories and sub-categories. This will usually necessitate the gathering of further data to elucidate perhaps quite specific points in order that a category can be saturated. Saturation of a category occurs when the collection of data and its analysis can add no further to the properties of the category. Categories may also be related to each other to provide an integrating framework. During axial coding the memos will now be developing the properties of categories and the relationship with sub-categories and in particular the integration of categories and the relationship between them.

As the number of saturated categories grow and the relationships between categories become established the categories can be unified around a 'core' category. This usually happens towards the end of an investigation. The core category represents the central phenomenon of the study and it is important that it is arrived at although the path to selecting it may be very difficult. In the later stages of an investigation the analyst may have identified several schemes that can link the data together. What is important is that a central category is arrived at and abstraction or generalisation can achieve this. Indeed the more abstract the core category then the more widely applicable it can be said to be to the organization. The 'filling in' of poorly developed categories is done at this stage, in order that all categories in the final integrative framework of categories are saturated. The memos at this stage are likely to be more elaborate and should thus be integrated, since they will form the basis of the final written account.

The two analytical techniques of theoretical sampling and constant comparison that are given in the legend of figure 3 are the means by which the Grounded Theory proceeds. These techniques relate the coding activities to the pool of data and memos that already exist. Theoretical sampling is an inductive technique that is used when the data do not exhaust the theoretical category that is being developed. The analyst must return to the domain until categories have been saturated. That is to say the analyst must sample particular categories to ascertain that its properties can not be elucidated further. Specific detailed questions need to be asked of participants related to the category that has been induced. This checks the scope as well as the depth of a category. The theoretical sampling in Grounded Theory is theory-driven and Strauss and Corbin (1998) emphasise that the grounds which decide what people, events or activities need to have further data collected on them are analytic grounds based on the emerging theory. As has been described above, as each new incident or concept emerges it needs to be compared against existing concepts and categories for both similarities and differences. The purpose of this constant comparison is essentially threefold: to ensure as far as is possible the analyst's neutrality by constantly challenging him/her with new data; to help achieve greater precision in grouping together like phenomena and then to further subdivide concepts which are variations on the first; and to ensure consistency in grouping like with like. The analyst must always look for patterns and variations and identify process where it occurs. Strauss and Corbin (1998) stress the importance of this constant comparison by saying that concepts and their dimensions 'earn' their way into the theory.

Grounded Theory has already had some limited exposure in the IS domain as a practical method predominantly in the knowledge elicitation area. Most notable contributions include Oliphant and Blockley (1991), Pidgeon, Turner et al. (1991) and Galal and McDonnell (1997). Although for each of these contributions no explicit organizational perspective is adopted and the procedures are used to code and categorise qualitative data.

To summarise the conceptual framework: ethnomethodology provides the organizational perspective for the collection of data and Grounded Theory provides reliable procedures for analysis. Within an action case the outcomes are both practical situated requirements and learning through reflection for the practitioner (requirements engineer)

\section{The Action Cases}

\section{The HVP study - domain}

The first action case domain was a three site veterinary practice in a city in the East Midlands, which we shall call HVP. One site is in the city centre and the others are situated 5 miles south and 5 miles Northwest of the city centre in large village locations. The Practice is a mixed practice in that it does both small animal and farm 
animal veterinary work. The Practice is a partnership with four equal share veterinary Partners, one salaried Partner, four full-time veterinary assistants and two part time veterinary assistants. There are thirteen practice receptionists including a reception supervisor at each site and eleven nurses including a nurse supervisor for each site. Additionally the Practice employs out of hours telephone receptionists who usually are the life partners of the vet on call. The general management of the Practice is through the Partners assisted by a full time Practice Manager and a Practice Accountant both of whom sit on the Practice management team. One accounts clerk and one administrative assistant provide additional administrative support for the Farm Office.

\section{The HVP study - intervention}

The nature of the intervention was to help the management team better understand its information needs prior to considering any investment in an IT infrastructure. They expected an outcome of the study to be an audit or evaluation of current work practices and recommendations for change, which would accommodate the introduction of computerised information systems. During the initial talks with the management team the developer made explicit the nature of the intervention methodology and the reasons for it. It was also established and agreed that the work would also have research outcomes. The team agreed that the outcomes of the research and the outcomes that they expected from the study were not in conflict.

The rationale for the study was linked to the management team's agreed strategy, which was presented through discussion rather than being formally documented. The management team in the last three years had seen an increase in the pressure on the city-centre site in terms of an increasing client base and the lack of appropriate accommodation to meet the increased demand. This led to the decision to open a new site, $W$, which would take some of the client numbers and also enable the practice to offer a purpose-built Farm Office and centre for farmers to visit to purchase veterinary products. The financial profile was such that funding the new premises was viable and the expectation was that the income from the new site would in the long term provide financial stability for the Practice. At the time of the study the management team realised that the growth in business since the opening of the $\mathrm{W}$ site had exceeded expectations and were considering ways to stabilise their client base such that a further site would not be required in the future. The management team broadly agreed that the move to a three-site practice had put, and would put, demands on their existing systems, procedures and management and staff.

The research/consultancy proceeded by establishing 'seed categories' for the interviews. Although a departure from the procedures of Grounded Theory, Miles and Huberman (1994) consider this a legitimate way to give initial focus for the interview questions. The three seed categories were understanding of job roles and responsibilities, decision-making processes and communication between the three sites. The first interviews were followed up with individuals and with groups in order to fill out emerging categories until the major categories were saturated. Saturation is achieved when transcript coding no longer adds to the dimensions or properties of the categories. This was followed in the analysis by the identification of the core category, which is the most abstract representation of the data. From the written accounts (known as memos in Grounded Theory) of each of these categories an understanding of the domain emerged which was grounded in the organization. The written accounts are given in full in Hughes 1998).

\section{The HVP study - the practical outcomes}

For the HVP management team a number of practical recommendations were made in the form of a report. The report was a distillation of the rich account produced by the use of the analysis method into a relatively thin document that largely ignored the process and context issues, which had led the consultant to make the recommendations. Briefly the recommendations were: to restructure the role of the practice manager; to specify management. roles in autonomous sites; to address formal communication systems such as day book and work rotas; to introduce computerised record keeping for client records in the first instance.

\section{The HVP study - the research outcomes}

For the researcher one of the important lessons was to consider this distillation into thin descriptions for the management to be a part of the methodology for future interventions. Other research outcomes included the excessive time taken to interview, transcribe, code and categorise the use of seed categories and the adaptation of the original methods into a practical context. What emerged was a revised framework. This revised framework was part of the action cycle and informed future work. The second action case used the adapted framework and methodology.

\section{The FP UK study - domain}

The second action case concerns a small manufacturing company, which we shall call FP UK, based in Northeast Wales. It is part of the FP Group consisting of three private limited companies, which are financially 
independent. The parent company FP A/S was registered in Denmark in 1952 to produce iron dust cores, ferrites and ceramic capacitors. FP UK offers a manufacturing capability for the production of most types of high quality inductors and transformers. Transformers are produced as custom designs and also in standard ranges. A highly flexible production facility ensures short lead times on custom designs as well as standard products. A small amount of business is with factored products (selling Danish manufactured products). Over the years the FP Group has forged strong links with technical institutions and other companies in the UK and the EU and is currently involved in several joint research and development projects with academic and commercial concerns within the EU. FP UK specifically has a design alliance with a German manufacturer and outlets for sales in both Italy and Germany. FP UK employs 18 full time salaried staff who work in administrative or management roles and an additional 20 who are production line workers.

\section{The FP UK study - intervention}

FP UK faced two major decisions with respect to the future of the organization. The first was to determine whether the future for FP UK lies either in manufacturing or in sales. The second and related decision was to determine an investment strategy in IT/IS linked to business objectives. The intervention was an audit to establish an IS investment strategy that would enable FP UK to make the decision regarding their future direction.

As with the action case given above, initial discussions included an explicit discussion of the research as well as the practical outcomes. In this case two seed categories were used since these had proved useful in the first case. These were understanding job roles and responsibilities and the impact of IT on work. A change suggested by the learning from the first case was to cut the time taken for transcribing, coding and categorising. This was particularly important in the FP UK case because of the tighter deadline set by the sponsors. This was achieved by exploiting the NUD.IST software package and by not fully transcribing all interviews. Using the NUD-IST package it was possible to listen to the taped interviews, transcribe the relevant passage, which would range from a couple of sentences to two or three paragraphs and augment existing categories or create new ones directly and therefore avoid the full transcription step. Because this seemed such a departure from the method, the taped interviews that were not fully transcribed were usually those where categories were being saturated. That is to say they were second or third interview with the same person. A core category was identified, 'demarcation' and both a full account from the coding was produced in addition to a management report.

\section{The FP UK study - the practical outcomes}

For FP UK the practical outcomes were an identification of an existing situation that showed a lack of a common understanding in the use of a variety of information systems and their relation to each other. Also a conflict between organizational goals, expressed by the managing director, and the goals of particular functional areas. The report, which was well received, recommended a single network infrastructure, internal IT integration, exploitation of external IT links, staff awareness issues, the appointment of an IT support manager and the inclusion of IS strategy as part of the business planning cycle.

\section{The FP UK study - the research outcomes}

Although the study was a departure from the original procedures for data analysis described by Glaser and Strauss (1967) it should be remembered that the original authors and users of the methods had no recourse to the use of such powerful software tools. In the original paper-based method great emphasis was placed on transcription since the transcribed document was also the physical medium for coding. That is to say margin notes in the form of codes were critical to the success of the method. However the introduction of the software package as the medium reduced the importance of the transcript except as evidence. (It is accepted that the tape itself is evidence but it is much less accessible than paper). Hence the sequence 'tape - transcribe - code' becomes 'tape - partial transcribe - code'. The difficulty with this is that when the developer needs to compare new documents with existing documents then only the codes or categories or partial transcript are available and therefore the taped interviews have to be listened to again. A further difficulty with this practical adaptation is the auditability of the method since although categories can be traced to the source document, the document itself is not a full account of the interview. Another consideration on this point is that the paradigm of inquiry for the method, ethnomethodology, is concerned with transcripts being in the interviewees' own words. Whilst the adaptation is true to this in terms of the partial transcript, it clearly does not contain all of the interviewees' own words and therefore may not be in keeping with the ethnomethodological perspective. However as with the HVP action case, and as noted in the introduction, this dilemma between practical outcome within time constraints and theoretical rigour whilst of interest to the developer, must be resolved in favour of the practical outcomes. Other research outcomes included the favourable use of the software package in time critical situations and the need for initial seed categories. 


\section{Lessons from the action cases}

In this section we explore some of the lessons of the action cases. In particular we consider what situated requirements may add to the requirements engineering process and we also consider the implications of this for the role of the requirements engineer.

\section{Situated Requirements}

The case has been presented to suggest that ways may be available to elicit situated requirements. It may be argued that the nature of the situated requirements in the form of a lengthy, although rich, report accompanied by diagrams of hierarchical categories is almost as impenetrable as the situation itself. Furthermore the result of any analysis which aims to give structure to ill-structured situations can at best be described as a snapshot and at worst described as 'pinning the butterfly'. That is to say that the use of the methods to elicit situated requirements in effect presents a description which is only a filter through which it may be claimed that some glimpse of some aspects of organizational life may be observed. The methodological questions thus remain about the use of any intervention method which necessarily affects the very area it purports to understand.

In practical terms however there are more positive lessons which may be learned. Situated requirement elicitation does provide a perspective on organizational life that other, more technically centred, methods ignore. Since by adopting an ethnomethodological perspective the method attends to 'meaning' in constructing social situations. Additionally the methods described may be said to provide a perspective through which the clients (users) better understand their own situation since it is articulated using their own words. A critical final point is that in the cases described the action case method enabled reflection on both the practical outcomes and also on the methods (process) of arriving at the situated requirements. This allowed for changes in the application of the methods and a fuller understanding for the consultant/researcher of the methods and their situated use. This has implications for the role of the requirements engineer if such perspectives are to be adopted and these are discussed next.

\section{Implications for the Role of the Requirements Engineer}

A new role needs to be considered for the requirements engineer which moves beyond the traditional role of expert and indeed beyond the emerging role of facilitator. It may be said that this move towards new roles has already begun in requirements engineering with the emergence of use case scenarios or with ethnographic approaches to the requirements organisational domain. In this latter case ethnography has been used in practical design settings to complement existing human centred methods of systems development based on the growing expectation that processes arising from social contexts should be informed by 'real world' analysis (Hughes et al., 1995). However the arguments presented here extend this role by emphasising the thinking skills of the requirements engineer and not solely the technical skills or the 'correctness' of method. This view is expressed in the literature as 'moral agent' (Walsham, 1993) or 'reflective practitioner' (Schon, 1983). It may be more appropriate to consider the role of the requirements engineer as 'bricoleur' which is not simply the jack of all trades but also the inventor. It is an appreciation that the tools, techniques and methods for understanding the organisational domain are insufficient to deal with each new situation and that the requirements process depends upon the individual requirements engineer to have a deeper understanding of the limitations of the process. This deeper understanding can be attained by explicitly stating any assumptions made about the organisation and the methods used and then reflecting upon and challenging these assumptions. There are two critical elements to this understanding - the first is an understanding of context (situation) aided by an explicit organisational perspective and the second is the dependence on the agent (requirements engineer) in that context and not a dependence on the methods used. The bricoleur role avoids the pitfall of treating selection of methods or methodologies as one might select tools from a toolbox since it incorporates the reflective (thinking) aspect. The reflective requirements engineer adapts methods and methodologies according to context and makes these judgements explicit. Finally it may be said that this is nothing more than 'you learn by your mistakes' or 'its just experience'. It would be damaging to leave that intuitive conclusion since it is in the articulation of the learning that is a further powerful element to reflection - it is the means by which one person's practical experiences become the shared learning of a community.

\section{CONCLUSION}

To summarise the arguments and the relationship between the action cases and the eliciting of situated requirements

The authors maintained in the introduction that there is an inherent weakness in the methods commonly associated with requirements determination. Specifically this relates to the lack of an explicit organisational perspective when intervening in organisations. As Potts and Newstetter (1997) note this is not unexpected since 
the requirements process is underpinned by a tacit positivistic philosophy. However if, as the paper suggests and in common with Potts and Newstetter (1997), we are to move to naturalistic methods which specifically address organisational perspectives then it is incumbent upon the requirements engineer to explicitly state the perspective and the underlying philosophy. Therefore through the action cases in which one of the authors took the role of requirements engineer, we outline an illustrative organisational perspective, ethnomethodology and an associated method for data analysis, Grounded Theory, both underpinned by a constructivist philosophy. There were two outcomes from the action cases. The first was an account of organisational life which represented the situated requirements (space in this paper prohibited a full version of the account). This was used in each of the two cases to inform both the sponsor of the study and the requirements engineer with respect to future design activities. The second was an articulation of the learning from the action cases (the objective of the paper). In the learning the authors identified the richness of situated requirements particularly in bringing about a greater shared understanding of the problem domain amongst users, sponsors and the requirements engineer. Also we identified a new role for the requirements engineer incorporating the role of reflective bricoleur. As with the reporting of any action-based research there may also be additional lessons for the reader that the authors have not identified.

It is important to iterate that the arguments presented here are not intended to persuade requirements engineers to use the illustrative framework given in this paper. The framework presented is but one means of intervention in, and understanding of, organizational life. We would maintain that critical reflection based on some explicitly stated theoretical or conceptual framework should be the basis for any requirements engineer who intervenes in organizational settings. We would extend Potts and Newstetter's (1997) conclusions and suggest additionally that in the majority of requirements projects where the underlying philosophy is positivist there is still a case for greater understanding of domain being achieved where the requirements engineer explicitly states his or her assumptions and reflects on the implications of them. Although the authors would maintain that this would be more limited than if their underlying perspective was constructivist. For the authors the intention is to develop this work particularly in the area of knowledge elicitation in large organisations where the sharing of contextual situated knowledge amongst those involved in IS/TT projects and processes is critical.

\section{REFERENCES}

Adam, F. and Fitzgerald, B. (1996) "A framework for analysing the evolution of the IS field - Can IS become a stable discipline?" in Coelho, J., Jelassi, T., Konig, W., Kremar, H., O'Callaghan, R. and Saaksjarvi, M. (Eds.) Proceedings of the 4th European Conference on Information Systems. Lisbon. July 2-4. pp.1732.

Argyris, C. and Schon, D. (1978) Organizational Learning: A Theory of Action Perspective. AddisonWesley, Reading.

Auramaki, E., Lehtinen, E. and Lyytinen, K. (1988) "A speech-act based office modelling approach" ACM Transactions on Office Information Systems. Vol. 6(2), pp. 126-152.

Baskęrville, R. and Wood-Harper, A.T. (1998) Diversity in information systems action research methods. European Journal of Information Systems, Vol. 7(2), pp. 90-107.

Brown, A. (1992) "Grounding Soft Systems Research" European Journal of Information Systems. Vol.1(6), pp. 387-395.

Checkland, P.B. (1981) Systems Thinking, Systems Practice. John Wiley and Sons Ltd. Chichester, UK.

Checkland, P.B. and Scholes, S. (1990) Soft Systems Methodology in Action. John Wiley and Sons Ltd. Chichester, UK.

Davis, G.B. (1982) "Strategies for Information Requirements Determination" IBM Systems Journal. Vol. 21(1), pp. 4-30.

Dobbie, M. and Hughes, J. (1993) "Realist Ethnomethodology and Grounded Theory: A Methodology for Requirements" Determination in Information Systems Analysis' Proceedings of the First British Computer Society Conference on Information Systems Methodologies. Edinburgh. pp. 311-321.

Dzida, W. and Freitag, R. (1998) "Making Use of Scenarios for Validating Analysis and Design" IEEE Transactions on Software Engineering. Vol. 24(12). pp.1182-1196.

Easterbrook, S. and Nuseibeh, B. (1993) "Managing inconsistencies in an evolving specification" Proceedings of the Second IEEE International Symposium on Requirements Engineering. York. UK. pp. 48-55.

Frakes, B., Batory, D., Biggerstaff, T., Kang, K. and Neighbours, J. (1998a) "Linking Domain Analysis and Domain Implementation" International Conference on Software Reuse. pp. 348-349

Frakes, W., Prieto-Diaz, R., and Fox, C. (1998b). "DARE: Domain Analysis and Reuse Environment". Annals of Software Engineering (5), pp. 125-141.

Galal and McDonnell (1997) Knowledge_based systems in context: a methodological approach to qualitative issues, AI \& Society, Vol. 11, pp. 104-121.

Garfinkel, H. (1967) Studies in Ethnomethodology. Prentice Hall. Englewood Cliffs, NJ.

Glaser, B. and Strauss, A.L. (1967) The Discovery of Grounded Theory: Strategies for Qualitative Research. Aldine. Chicago. 
Goguen, J.A. (1992) "The dry and the wet" in Falkenberg, E.D., Rolland, C. and El-Sayed Nasr-El-Dein El Sayed (Eds.) Information Systems Concepts: Improving the understanding. Elsevier Science Publishers B.V. (North-Holland) pp. 1-17.

Goguen, J.A. and Linde, C. (1993) "Techniques for Requirements Elicitation" IEEE International Symposium on Requirements Engineering. pp. 152-164.

Goguen, J.A. (1994) "Requirements Engineering as the reconciliation of social and technical issues" in Jirotka, M. and Goguen, J.A. (Eds.) Requirements Engineering: Social and Technical issues. Academic Press. London.

Hughes, J and Howcroft, D. (2000) Grounded Theory: Never Knowingly Understood New Review of Information Systems Research (forthcoming)

Hughes, J., O'Brien, J., Rodden, T., Rouncefield, M. and Sommerville, I. (1995) "Presenting Ethnography in the Requirements Process" Proceedings of the Second IEEE International Symposium on Requirements Engineering, York, UK

Hughes, J. (1998) The Development of the GIST (Grounding Information SysTems) Methodology: Determining Situated Requirements in Information Systems Analysis. Ph.D. Thesis. Information Systems Research Centre, University of Salford, Salford, UK.

Hughes, J. and Wood-Harper, A.T. (1999) "Systems Development as a Research Act" Journal of Information Technology. Vol.14(1) pp. 83-94

Hughes, J., O'Brien, J., Rodden, M., Rouncefield, M. and Sommerville, I. (1993) "Presenting ethnography in the requirements process" Proceedings of the Second IEEE International Symposium on Requirements Engineering. York, UK. pp. 27-34.

Jackson, M. (1988) "A Discipline of Description" Requirements Engineering. Springer-Verlag, London. Vol 3, pp 73-78

Jacobson, I. et al. (1992) Object-Oriented software Engineering, a Use Case Driven Approach. AddisonWesley.

Jirotka, M. and Goguen, J.A. (Eds.) (1994) Requirements Engineering: Social and Technical Issues. Academic Press, London.

McDermid, J.A. (1994) "Requirements Analysis:orthodoxy, fundamentalism and heresy" in Jirotka, M. and Goguen, J.A. (Eds.) Requirements Engineering: Social and technical issues. Academic Press. London. pp. $17-40$.

Miles, M.B. and Huberman, A.M. (1994) Qualitative Data Analysis. Second Edition. Sage. UK.

Oliphant, J. and Blockley, D.I. (1991) "Knowledge-based system: Advisor on the Earth Retaining Structures" Computers and Structures. Vol. 40(1) pp. 173-183.

Pidgeon N.F., Turner, B.A. and Blockley, D. I. (1991) "The use of Grounded Theory for conceptual analysis in knowledge elicitation" International Journal of Man-Machine Studies. Vol. 35(2) pp. 151-173.

Potts, C. and Newstetter, W.C (1997) "Naturalistic Inquiry and Requirements Engineering: Reconciling their theoretical foundations" Proceedings of the IEEE International Conference on Requirements Engineering. pp. 118-127.

Reason, P.(1994) Three approaches to participative inquiry. In Denzin, N.K. and Lincoln, Y.S. (eds.), Handbook of Qualitative Research. Sage. London. pp. 324-339.

Regnell, B., Kimbler, K. and Wesslén, A. (1995) "Improving the USE Case driven approach to requirements engineering" Proceedings of the second IEEE International Symposium on Requirements Engineering. York, UK. pp. 40-47.

Schon, D.A. (1983) The reflective practitioner. How professionals think in action Basic Books, USA.

Strauss A and Corbin C (1998) Basics of Qualitative Research: Techniques and Procedures for Developing Grounded Theory, Sage, London, 2nd edition.

Suchman, L. (1987) Plans and Situated Actions: The Problem of Human-machine Communication. Cambridge University Press. Cambridge, UK.

Sutcliffe, A. and Maiden, N. (1998) "The domain theory for requirements engineering" IEEE Transactions on Software Engineering. Vol. 24(3), pp. 174-197.

Valusek, J.R. and Fryback, D.G. (1985) "Information requirements determination: Obstacles within, among and between participants" Proceedings of the SIGCPR ACM Conference on End-User Computing Minneapolis, USA.

Vidgen, R and Braa, K. (1997) Balancing interpretation and intervention in information systems research: the "action case" approach. In Lee, A., Liebenau, J. and DeGross, J. (eds.), Proceedings of the IFIP WG8.2 International Conference on Information Systems and Qualitative research. Philidelphia, USA

Walsham, G. (1993) "Ethical Issues in Information Systems Development - The Analyst as Moral Agent" in Avison, D., Kendall, J.E. and DeGross, J.I. (Eds.) Human, Organizational and Social Dimensions of Information Systems Development. North Holland. Amsterdam. pp.281-294.

Waters, M. (1994) Modern Sociological Theory. Sage. London, UK. 